\title{
ECONOMÍA Y FINANZAS
}

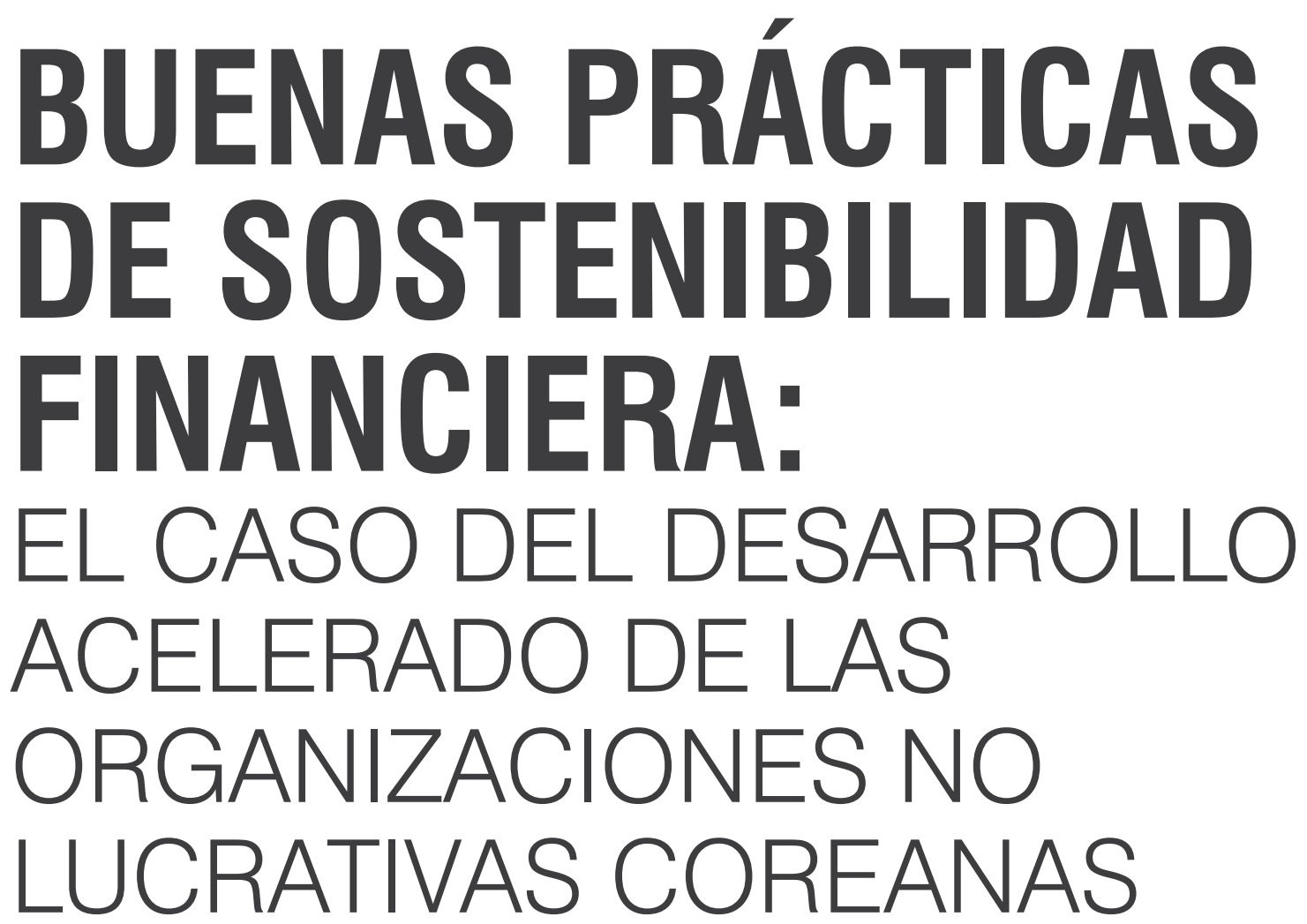

BEST PRACTICES OF FINANCIAL SUSTAINABILITY: THE CASE OF ACCELERATED DEVELOPMENT OF KOREAN NON-PROFIT ORGANIZATIONS

$>>$ 


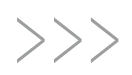

\section{Dayanne Alejandra Acosta Santamaría}

Universidad Industrial de Santander disalejasantamaria@gmail.com

\section{Jenny Carolina Betancur Marín}

Universidad Industrial de Santander carolinahalcon@gmail.com

\section{Abstract}

Beyoungri Danche ${ }^{1}$ success depends on the financial strategies their leaders use to make it sustainable over time. A literature review of best practices in Korean Beyoungri Danche and an exploratory research of web content in three successful organizations allow the learning of tactics from another culture that has demonstrated a high organizational level and strengthen the dialogue around a topic of common interest.

\section{Keywords}

Nonprofit organizations, Republic of Korea, good practice codes, financial sustainability.

\section{Resumen}

El éxito de las Beyoungri Danche depende de las estrategias financieras que sus líderes utilizan para hacerlas sostenibles en el tiempo. La recopilación de buenas prácticas de las Beyoungri Danche coreanas en la literatura y una investigación exploratoria de contenidos web de tres organizaciones exitosas, permite aprender tácticas de otra cultura que ha demostrado un alto nivel organizacional y fortalecer el diálogo alrededor de un tema de interés común.

\section{Palabras clave}

Organización sin ánimo de lucro, República de Corea, códigos de buenas prácticas, sostenibilidad financiera.

\section{Introducción}

El sector no lucrativo es un componente estratégico de empoderamiento social y construcción de comunidad, que se ha convertido en una fuerza económica a nivel nacional e internacional (Cho, 2007; Sirianni \& Friedland, 2001). Sin embargo, dada la transformación y el crecimiento de las sociedades, las Beyoungri Danche se enfrentan a más y nuevas necesidades, lo que incrementa la complejidad para que sus dirigentes logren su sostenibilidad (Jeong B., 2013; Holtzhausen, 2013). Por ejemplo, los líderes coreanos de estas instituciones, parecen estar limitados por la financiación pública concedida por los gobiernos locales y el gobierno central, en particular en el establecimiento de objetivos y la asignación de recursos (Jung \& Moon, 2007). En Corea del Sur es necesario desarrollar habilidades técnicas para coordinar esfuerzos y reducir las actividades duplicadas de las Beyoungri Danche, que debilitan considerablemente su capacidad de utilizar los recursos compartidos y apoyar acciones comunes (Choi \& Yang, 2011). Estas mejoras incluyen la planificación estratégica, técnicas institucionalizadas de recaudación de fondos y la búsqueda de apoyo institucional a largo plazo en lugar de subvenciones para proyectos a corto plazo de donantes privados (Kim H. , 1997). La sostenibilidad financiera de las Beyoungri Danche es una preocupación tanto coreana (Jeong S., 2008), como colombiana (Echeverri, 2008). Por tanto, la identificación de tendencias y estrategias en este campo puede aportar soluciones inexploradas a las organizaciones de nuestro país. Así mismo, esta investigación permite explorar la dimensión motivacional altruista de los

1 Este trabajo de investigación utiliza el término coreano "Beyoungri Danche" por ser el más inclusivo para referirse a todas las organizaciones que no pertenecen al sector lucrativo ni al gubernamental. Beyoungri significa sin ánimo de lucro y Danche significa organización (Kim \& Hwang, 2002). 


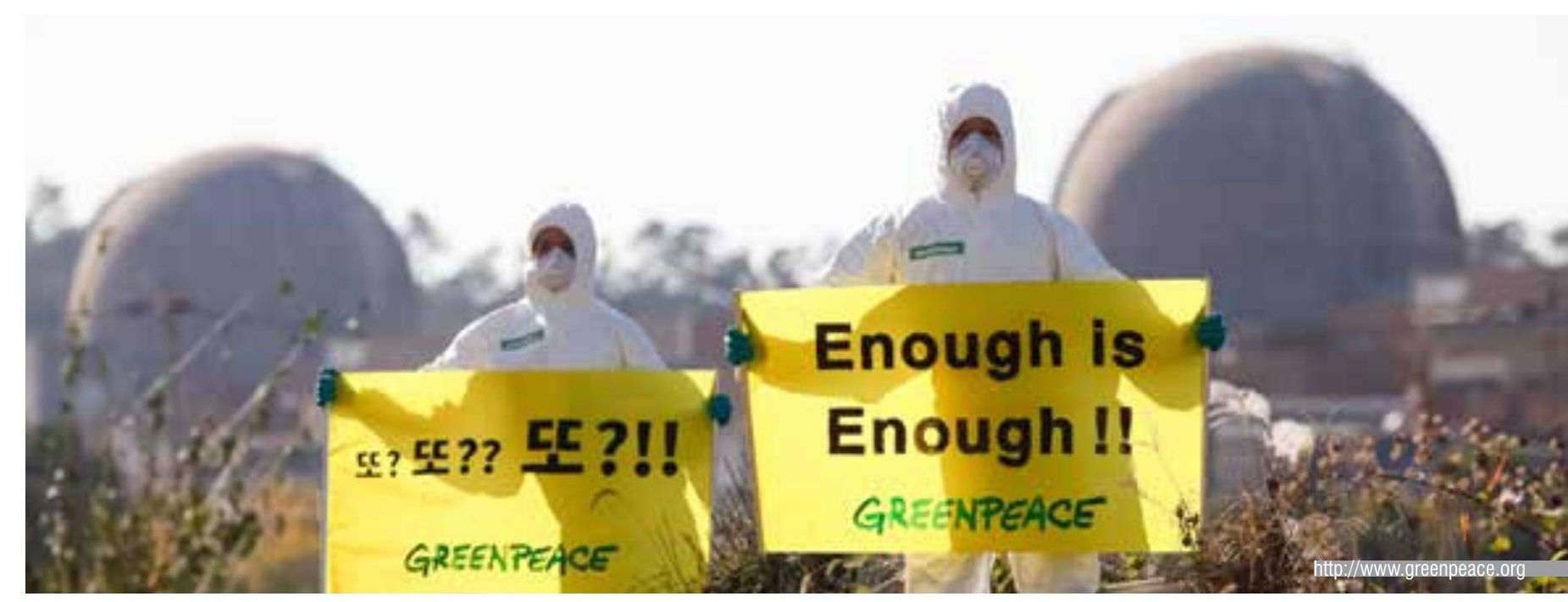

coreanos quienes han tenido que sobrevivir difíciles situaciones, y aun así han demostrado un alto nivel organizacional (Chung, 2003).

Otros países pueden ofrecer experiencias de organizaciones más robustas, sin embargo, es precisamente el surgimiento y desarrollo acelerado de las Beyoungri Danche en Corea del Sur un atractivo de estudio para las empresas con un corto historial. Núcleos sustanciales de influencia en la sociedad e instrumentos de desarrollo con diversas formas, las Beyoungri Danche coreanas, involucran varias disciplinas de las ciencias sociales y se han destacado tradicionalmente por la promoción de los derechos humanos, la democracia y la salvaguardia contra los poderes abusivos del gobierno y las grandes empresas (Choi \& Yang, 2011).

\section{Metodología}

Una vez identificado un modelo de medición de la sostenibilidad financiera para las Beyoungri Danche (Tuckman \& Chang, 1991; Keating, Fischer, Gordon, \& Greenlee, 2005), se realiza una búsqueda en la base de datos WEB OF KNOWLEDGE de los artículos correspondientes a los criterios del modelo con las palabras "nonprofit" AND "accountability," "Revenue concentration," "Operating Margins," "commercial income" y "endowment." Con la ayuda del software Vantagepoint, para evitar repetición de registros y clasificarlos de acuerdo a las palabras clave, finalmente se revisan 84 artículos que se documentan de acuerdo a la relación criterio - buena práctica de sostenibilidad financiera.

\section{Revisión de la literatura científica de la sostenibilidad financie- ra de las beyoungri danche coreanas}

En términos generales la sostenibilidad global de una Beyoungri Danche, debe entenderse como un desafío continuo para lograr la misión social eficiente y eficazmente, teniendo en cuenta el impacto social y ambiental de las actividades y cumpliendo requisitos continuamente en todos los aspectos que son críticos a su supervivencia. La sostenibilidad financiera es un componente clave de la sostenibilidad organizativa y es uno de los factores decisivos para el alcance de la misión social (Abraham, 2003). 


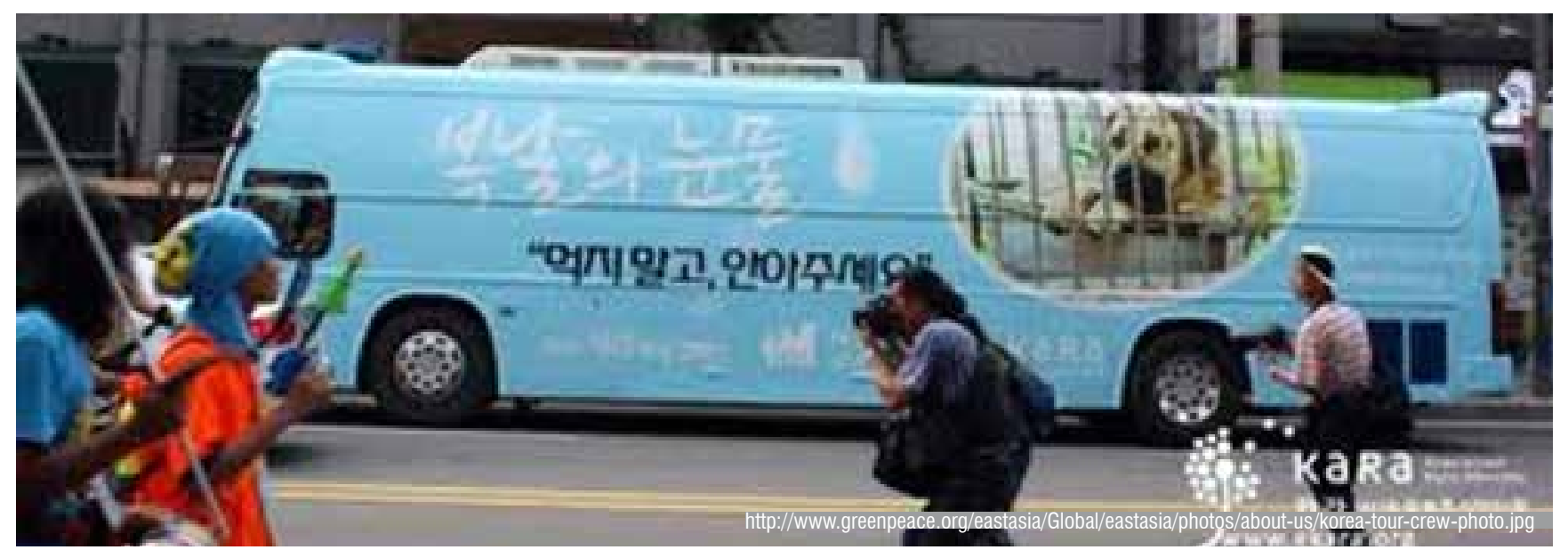

Los retos de establecer la capacidad y la sostenibilidad financiera son fundamentales para el funcionamiento organizacional (Bowman, 2011). Existe una tensión entre la capacidad de mantener la viabilidad financiera en el largo plazo y la persecución de la misión (Alexander, Nank \& Stivers, 1999; Anheier \& Seibel, 2001; Salamon, 2002), esta preocupación ejerce presión sobre las operaciones del día a día de las Beyoungri Danche coreanas y en la toma de decisiones, pues muy a menudo parece que se debe elegir a favor de una $u$ otra (Sang \& Seung, 2012).

Según Bowman (2011), una organización sostenible en el largo plazo, pero insostenible en el corto plazo presentará escasez crónica de dinero en efectivo. Por el contrario, una organización sostenible en el corto plazo pero no en el largo plazo, puede tener suficiente dinero en efectivo, sin embargo, la inflación causa que el valor de sus activos se erosione con el tiempo. Esto a su vez hará que la cantidad y calidad de los servicios disminuya, a menos que se hagan campañas para atraer capital e infusiones de nuevos activos. Para las organizaciones lucrativas y no lucrativas la sostenibilidad financiera consiste en recursos que dan la habilidad de aprovechar las oportunidades y reaccionar a las amenazas inesperadas, manteniendo las operaciones generales y un buen patrón de rendimiento y viabilidad (Bowman, 2011).

Para entender las diferencias en los factores relacionados con la sostenibilidad financiera entre organizaciones lucrativas y no lucrativas, es importante identificar y entender los objetivos a largo plazo de la organización. Por ejemplo, el objetivo estratégico final de las organizaciones con fines de lucro es la adquisición de beneficios y cuota de mercado, mientras que los resultados financieros de las organizaciones no lucrativas son un medio para el cumplimiento de la misión social (Hackler \& Saxton, 2007).

Las Beyoungri Danche obtienen la mayoría de sus ingresos de contribuciones de caridad o créditos fiscales; y miden la eficiencia y la efectividad de sus operaciones en el alcance de su misión social, que es su objetivo estratégico. Se enfrentan al desafío de equilibrar la necesidad de rentabilidad en el largo plazo, como un medio para apoyar sus programas y servicios, dando prioridad a su misión social y a los planes organizacionales que identifican oportunidades para gestionar el flujo financiero a corto plazo, mientras se avanza hacia el cumplimiento a largo plazo de los objetivos sociales y financieros (Sontag et al., 2012; Abraham, 2003). Abraham (2003), concluye que la sostenibilidad financiera de una Beyoungri Danche es considerada como su capacidad de obtener ingresos en respuesta a una demanda y sostener sus procesos productivos a un ritmo constante, obteniendo resultados y superávit. 


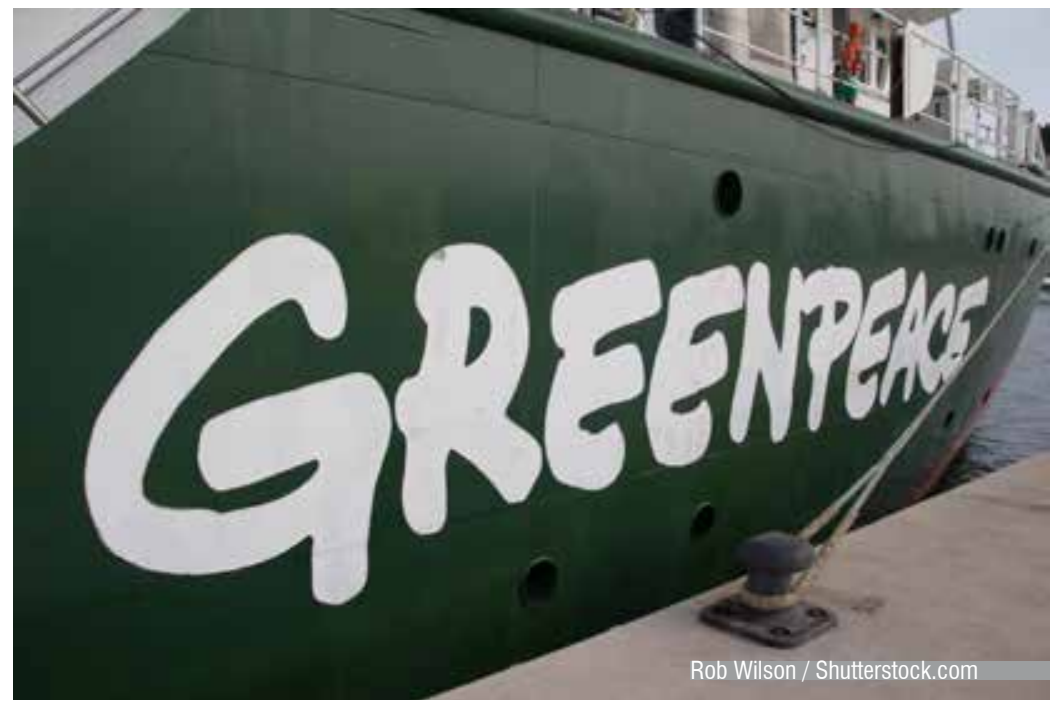

A continuación se describe cada uno de los criterios definidos por Tuckman \& Chang (1991) y Keating et al. (2005), que permiten medir el estado de la salud financiera de las Beyoungri Danche, con las respectivas prácticas financieras identificadas en la literatura.

Criterio 1: rendición de cuentas. En la última década, los donantes han comenzado a exigir documentación detallada de los resultados de las entidades en busca de su apoyo (Zimmerman \& Stevens, 2006). La construcción de la capacidad de seguimiento de las operaciones y la comunicación directa a financiadores es imprescindible, si las Beyoungri Danche esperan establecer un apoyo financiero. Sin embargo, la rendición de cuentas constituye un esfuerzo muy grande para algunas Beyoungri Danche, que necesitan la financiación, pero carecen de tiempo y personal para desarrollar y mantener programas de medición de resultados integrales (Zimmerman \& Stevens, 2006). La rendición de cuentas es tanto una obligación legal como ética de las organizaciones que utilizan recursos recibidos para continuar su misión caritativa (Gordon, Khumawala, Kraut \& Neely, 2010), inversionistas y donantes desean obtener acceso a información actualizada acerca de las operaciones y las finanzas de las Beyoungri Danche (Jeong B., 2013; Bray, 2010). A continuación, se destacan las prácticas de rendición de cuentas de alto impacto:

Mantener una contabilidad confiable. Una Beyoungri Danche debe mostrar su contabilidad y evaluación de desempeño para recibir fondos; como resultado se ha hecho gran énfasis en demostrar efectividad y eficiencia en el registro de cuentas (Kim J. 2006; Frumkin \& Andre-Clark, 2000; Kellock, Beattie, Livingstone, \& Munro 2001). Si una organización tiene un buen sistema de contabilidad financiera, su capacidad para enfrentar choques financieros será fácilmente previsible y medible.

Desde una perspectiva interna, los sistemas de rendición de cuentas se pueden vincular a sistemas apropiados de control interno de los asuntos financieros garantizando la provisión de información contable fiable, necesaria para una gestión financiera responsable (Sopher, 1998). Existe un acuerdo general en que los requisitos para un buen control de la gestión interna incluye personal competente, asignación de responsabilidades, división del trabajo, separación entre la contabilidad y el registro diario de gastos, registros y equipos adecuados, rotación de personal, auditoría interna y protección física de los activos (Anthony \& Young, 1994). 


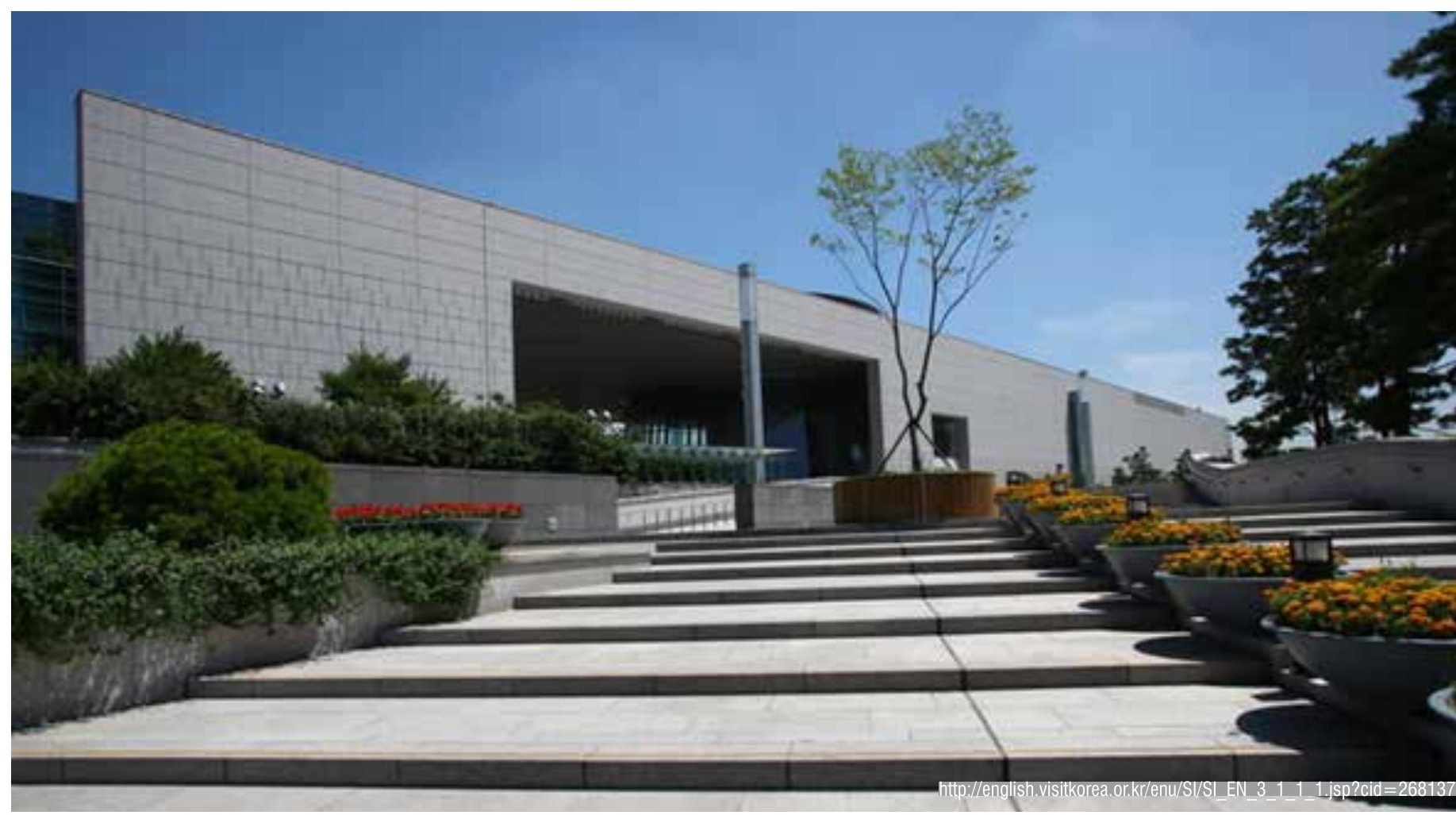

Sin embargo, las expectativas de contabilidad se extienden a la gestión del control en áreas de planeación y presupuesto, la recaudación de fondos, la asignación de recursos, el mantenimiento de registros, el seguimiento y evaluación, la presentación de informes y auditorías (Elkin, 1985). Tales controles son esenciales para las Beyoungri Danche pues "proporcionan datos actuales sobre dónde está la organización y datos de proyecciones de a dónde se desea llegar" (Abraham, 2003).

Utilizar un programa de evaluación para demostrar valor. Bell, Masoka \& Zimmerman (2010), proponen un marco para la evaluación de la sostenibilidad en las Beyoungri Danche usando una "línea de base dual" que determina la sostenibilidad sobre la base de la rentabilidad financiera y el impacto misional de los programas que ofrecen. La rentabilidad vista como los beneficios obtenidos con base a los costos directos del programa y un porcentaje de gastos administrativos, es más clara que el "cálculo" de los programas con mayor impacto misional. Una evaluación estructurada de los programas puede resultar difícil para muchas organizaciones que no disponen de la capacidad para realizarla.

En la mayoría de los casos, los programas ejecutados se alinean con la misión y con frecuencia, con las prioridades de los inversionistas y las agencias gubernamentales. Sin embargo, el mantenimiento de muchos programas o actividades que sólo se alinean un poco, dan lugar a excesos financieros y carga organizacional que puede poner en peligro la sostenibilidad a largo plazo. A su vez, la pregunta de qué programas y servicios demuestran el mayor impacto es la clave en la evaluación de la sostenibilidad (Sontag et al., 2012). En un esfuerzo para eliminar parte de la subjetividad en la evaluación del impacto de los programas y servicios, Bell et al. (2010), proporcionan siete 
factores para evaluar el impacto relativo que ha sido probado en las Beyoungri Danche: (1) la alineación con la misión central; (2) la excelencia en la ejecución; (3) escala o volumen; (4) profundidad; (5) llenar un vacío importante; (6) construcción de la comunidad; y (7) apalancamiento. Los autores recomiendan el uso de hasta cuatro de estos criterios para evaluar un programa ofrecido por la organización sin ánimo de lucro. Estos criterios son diseñados para hacer una "reflexión estructurada" y pueden hacerse como un ejercicio de grupo. También es una oportunidad de asignar pesos a los criterios seleccionados (Park \& Kim, 2004).

Utilizar los informes anuales para comunicar resultados. Estudios académicos sugieren que los donantes incrementan su intención de donación cuando la información contable es clara y visible (Parsons, 2007; Buchheit \& Parsons, 2006). Para las Beyoungri Danche coreanas la información de desempeño misional es a menudo la parte más interesante del reporte anual para el público en general y, es muy relevante para cualquier decisión de apoyar una organización a través de donaciones o voluntariado (Lyons \& Samiul, 2002). Gordon et al. (2010) describen cinco prácticas prometedoras para los informes anuales en el sector sin fines de lucro: a) integridad: incluir los estados financieros auditados en el informe anual; b) accesibilidad: hacer disponibles los informes anuales a los inversores y otras partes interesadas; c) transparencia en la información financiera: proporcionar reportes de información financiera que permita al usuario "ver a través" de los números y comprender las actividades y eventos subyacentes retratados; d) divulgación completa: presentar suficiente información en los informes anuales para asegurar que los estados financieros provean todos los datos y resuelvan cualquier duda; f) pertinencia: la información más relevante que una empresa sin fines de lucro puede proporcionar a sus grupos de interés, debe resaltar los logros relacionados con la misión organizacional, demostrar gastos excesivos en el costo de operación puede indicar que se pudieron haber prestado más servicios, para los donantes e inversionistas, la misión es el motivador más importante cuando se trata de dar.

Criterio 2: diversificación de ingresos no comerciales. La concentración de ingresos de donantes e inversionistas debe sostenerse desde dos principios claves para la sostenibilidad: diversidad y distribución. La diversificación de las fuentes de ingresos aumenta la sostenibilidad financiera debido a la probabilidad de que todas las fuentes no se vean afectadas por la misma crisis económica (Bryce, 1992). Por el contrario, entre menos fuentes de ingresos tengan las organizaciones, son más vulnerables económicamente a las recesiones (Trussel, 2002; Tuckman \& Chang, 1991). Las Beyoungri Danche cuentan con un conjunto diverso de fuentes para sostener sus operaciones, entre los cuales están: organismos de gobierno local, nacional e internacional; instituciones financieras; fundaciones; organizaciones filantrópicas y donantes particulares (Bessel, Williams \& Klak, 2011; Carman, 2001). En segundo lugar, una organización con igual distribución de ingresos de diversas fuentes será más sostenible financieramente, que una que recibe la mayor parte de sus ingresos de una sola fuente (Bak, 2001). Por tanto, cuanto mayor sea el número de fuentes de ingresos y estas contribuyan equitativamente a los ingresos totales, es más sostenible financieramente la organización. El modelo de salud financiera utiliza una medida operativa que incorpora diversidad de fuentes de ingresos y distribución de estas fuentes (Abraham, 2003).

A continuación, se destacan prácticas prometedoras que las organizaciones no lucrativas pueden seguir a fin de no llegar a ser excesivamente dependientes de una sola fuente de financiación. 


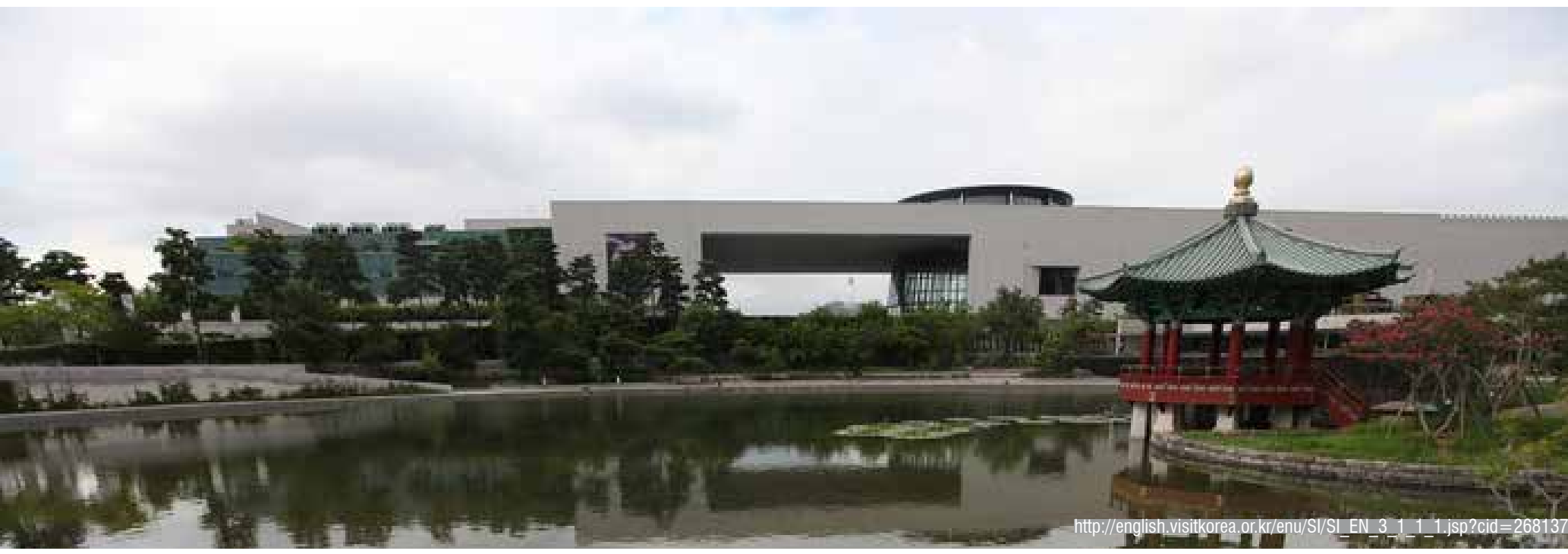

Desarrollar un plan de recaudación de fondos coherente. La forma en que las Beyoungri Danche responden a la incertidumbre financiera es crucial para cumplir con las metas y posicionarse en el futuro (Mosley, Maronick \& Katz, 2012), muchos planes de recaudación de fondos y de hecho una gran parte de las carteras financieras, se cumplen a través de los esfuerzos de recaudación de donaciones filantrópicas; se ha encontrado que la ausencia relativa de donaciones locales es más una cuestión de "voluntad de dar" que de "capacidad de dar" (Bessel et al., 2011).

Existe una relación significativa entre el porcentaje de donaciones individuales y los fondos recaudados por miembros de la junta directiva; Bessel et al. (2011), encuentran que en cuatro de las nueve agencias estudiadas, son los miembros de la organización quienes participan en la recaudación de fondos anuales, garantizando el presupuesto dentro de su área de servicio. Esto sugiere la importancia de la conexión emocional en la recaudación de fondos. A su vez, los desafíos alrededor de la obtención de fondos incluyen pensar un argumento de "¿por qué esta organización y no otra?" establecer una conexión social-emocional con los donantes para convencerlos de por qué este debería ser "su problema" y establecer un flujo constante de donación (Sontag et al., 2012).

La recaudación de fondos debe utilizar técnicas perfectamente desarrolladas y planificadas. Recaudar no es salir a la calle y pedir dinero, nada debe quedar al azar. Las recaudaciones de fondos a perpetuidad deben ser tenidas siempre en cuenta, serán bases sólidas sobre las cuales pueda mantenerse y crecer la organización, así como respaldo para las recaudaciones ocasionales (Maglieri, 1997).

El desarrollo de un plan de recaudación de fondos coherente para abordar el criterio discutido previamente y promover la misión de la organización es imprescindible. Un plan estratégico de recaudación de fondos ofrece una oportunidad para examinar lo que está funcionando bien y donde hay oportunidades para mejora (Bray, 2010).

Entre algunas de las tareas que Bray sugiere para el desarrollo de un plan de recaudación de fondos se destacan las siguientes: a) determinar una meta razonable para trabajar, b) evaluar los mayores activos de recaudación de fondos, c) crear una estrategia de recaudación, d) hacer que la organización luzca valiosa para hacer una contribución, e) agradecer a los contribuyentes, 
f) entender qué motiva a los contribuyentes, g) atraer nuevos contribuyentes, h) anotar la estrategia en un documento corto y fácil de entender.

Incorporar técnicas innovadoras de recaudación de fondos. La innovación en la recaudación de fondos es un pilar para el éxito y es comprendida como la habilidad para continuamente transformar el conocimiento y las ideas en nuevas formas de recaudación (Sidel, 2010). Las Beyoungri Danche tienden a quedarse en el tiempo y desaparecer por su rigidez, cuando no reinventan estrategias creativas en su operación. Una vez completada la revisión de literatura se encontró que las técnicas innovadoras de recaudación de fondos incluyen:

Círculos de donación. Implican grupos de individuos que ponen en común sus recursos y luego deciden juntos dónde donarlos. También incluyen con frecuencia compromiso social, educacional y voluntariado (Bidet, 2002). Los círculos de donación también se basan en la identidad y han tenido éxito con la participación de la juventud y el género femenino, son particularmente ventajosos en la consecución de recursos menos tangibles como nuevos voluntarios, nuevos contactos, prestigio y nuevos donantes (Eikenberry, 2008).

Crowdfunding o financiación masiva. Es una cooperación colectiva, llevada a cabo por personas que realizan una red para conseguir dinero $u$ otros recursos. Los resultados de un estudio empírico acerca de la relación entre donantes, empresarios y plataforma de crowdfunding en las artes escénicas realizado por Boeuf, Darveau \& Legoux (2014), revelan que para que un proyecto alcance su objetivo debe tener en cuenta los siguientes factores claves: asegurarse de que el proyecto es convincente; captar emociones del público y entusiasmar con una idea singular o con un tema o causa que apasione; aprovechar públicos apasionados existentes; integrar al público en el proceso de desarrollo respondiendo a los comentarios; preparar materiales promocionales de alta calidad e invertir en grandes esfuerzos de promoción, que inspiren confianza entre los potenciales contribuyentes; ofrecer incentivos convincentes y proporcionar un plan de asignación de fondos claramente definido. El comportamiento pro-social de los actores involucrados en el proceso de crowdfunding subraya las afinidades entre este fenómeno y el espíritu de reciprocidad que es inherente a la economía del regalo.

Eventos mediáticos de caridad. Los eventos mediáticos de caridad, donde la filantropía parece ser parte de la ontología de las celebridades quienes añaden un aura de exclusividad y glamour y que son motivadores que contribuyen a la mercantilización de la caridad. Estas campañas ofrecen entretenimiento, empatía y desarrollan grupos de pares y redes que animan a dar (Driessens, Joye, \& Biltereys, 2012).

Criterio 3: márgenes de operación. Teóricamente y en repetidas ocasiones ha sido argumentado, también demostrado que solo las organizaciones eficientes con alto margen de operación sobreviven cuando la competencia es fuerte (Machlup, 1967; Giroud \& Mueller, 2010; Giroud, 2011). La relación de margen operativo se expresa como el porcentaje de los resultados operativos netos de la organización sobre el ingreso total. Si una organización tiene un margen de operación bajo o negativo, entonces tendrá poco o ningún superávit sobre el cual trabajar antes de tener que recortar los servicios (Young, 2008). En consecuencia una organización sin ánimo de lucro con alto o al menos positivo, margen de funcionamiento, será financieramente sostenible (Abraham, 2003). Partiendo del análisis del estado de resultados, se recomienda: 


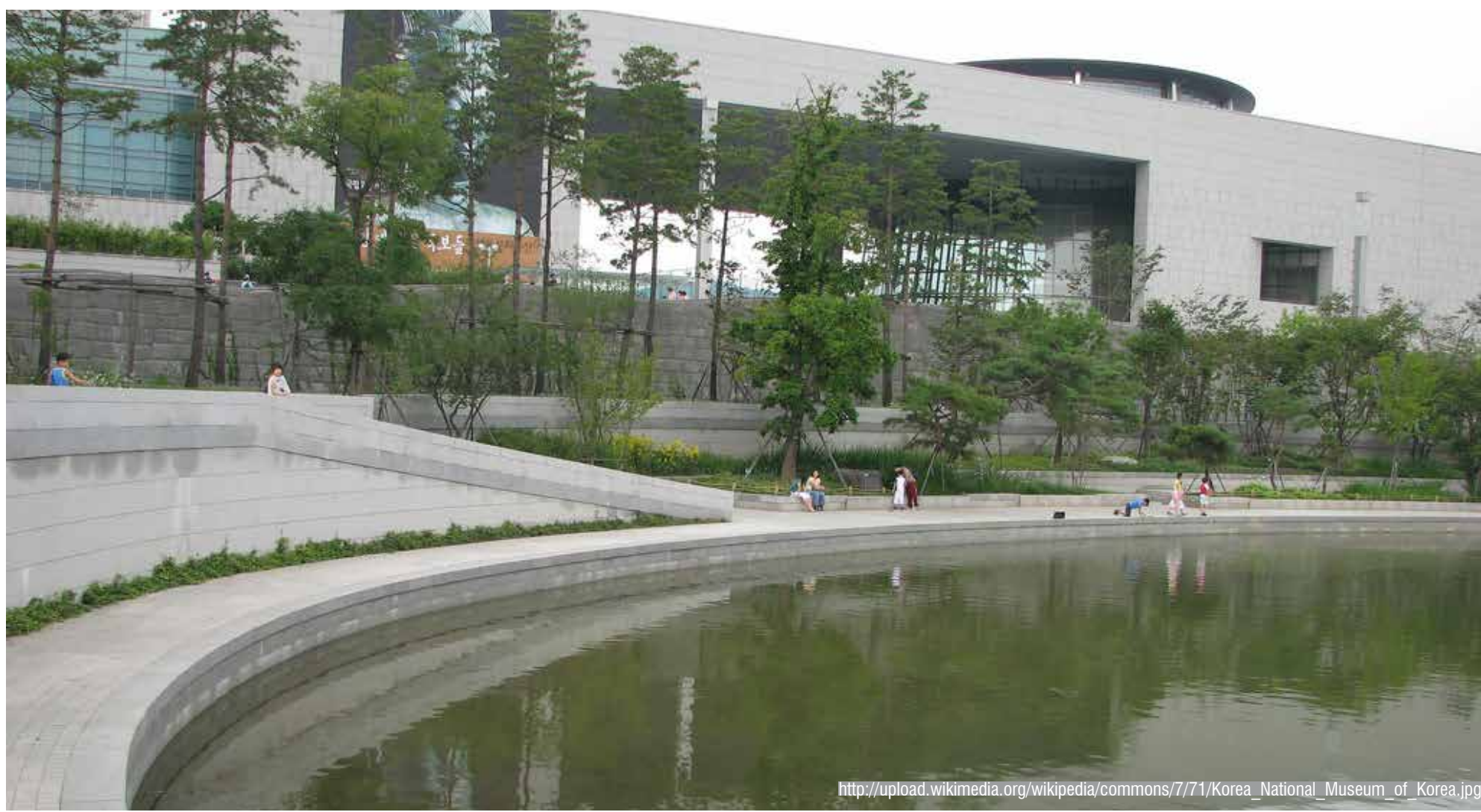

Aumentar ingresos y reducir gastos operativos. Reducir gastos y costos en la prestación de servicios, programas y comercialización de productos, mediante negociaciones con proveedores y la asociatividad con otras empresas lucrativas y/o del mismo sector, y aumentar los ingresos, diversificándolos como se ha señalado en criterios anteriores. Asimismo, la organización debe compararse con la media del sector, para analizar su posicionamiento en el mercado, y realizar periódicamente un benchmarking para evidenciar las mejores prácticas operativas y aplicarlas en la ejecución de su misión social.

Criterio 4: ingresos comerciales. Estos se toman como el porcentaje del total de ingresos que se obtienen por venta de mercancía, comisiones de servicios del programa y cargos pagados por los clientes. Una empresa será menos propensa a experimentar dificultades financieras si se basa más en ingresos comerciales que en ingresos de donantes o contribuciones que a menudo no son recurrentes y sensibles a los cambios según las condiciones económicas y políticas (Kim \& Hwang, 2002; Keating, et al. 2005)

Dado que las Beyoungri Danche son inherentemente sociales, los académicos han establecido que el emprendimiento social en el sector ocurre cuando una Beyoungri Danche genera parte de sus ingresos a través de la venta de productos y servicios (Thompson, 2002; Wallace, 1999; Boschee \& McClurg, 2003; Kerlin, 2005). Los defensores de la práctica argumentan que los ingresos comerciales son benéficos y proveen fondos suplementarios, estabilidad de ingresos, y autosuficiencia (Choi \& Yang, 2011; Brinckerhoff, 2000; Carroll \& Stater, 2009).

Generar ingresos requiere identificación y explotación de oportunidades de mercado, situaciones en las que los bienes y servicios pueden ser vendidos a mayor valor que el de su costo de producción. La generación de ingresos es por su naturaleza llamada a crear valor agregado. La diferencia entre la 
creación de valor por organizaciones lucrativas y no lucrativas es que el valor económico creado está motivado por el valor social (Austin, Stevenson, \& Wei-Skillern, 2006; Boschee, 1995). A continuación se muestran prácticas prometedoras para aumentar los ingresos comerciales:

Emprender actividades comerciales en forma gradual. Boschee \& McClurg (2003) y Jeong S. (2008), afirman que todas las Beyoungri Danche tienen oportunidades para obtener ingresos en el marco de sus programas existentes, aconsejan iniciar por estas oportunidades pequeñas que pueden llevar a la explotación de una oportunidad de alto impacto. Una vez se han realizado con éxito varias estrategias de ingreso, es posible considerar el emprendimiento con objetivos más ambiciosos.

Separar la actividad comercial. Los pioneros en el campo también recomiendan crear entidades comerciales completamente separadas de las operaciones cotidianas de la organización, con un personal independiente y políticas de retribución separadas e incluso un consejo de administración independiente (Boschee \& McClurg, 2003).

Realizar grandes eventos. En la literatura los grandes eventos realizados por las Beyoungri Danche, consisten a menudo en eventos participativos, deportivos o de entretenimiento, los cuales además de tener una inscripción paga, se convierten en el medio para promover la compra de productos (Park \& Kim, 2004). Los resultados del estudio realizado por Filo, Funk, \& O'Brien (2008), revelan que la combinación de la motivación social, intelectual o deportiva, junto con el deseo de ayudar a los demás, tienen una influencia positiva en la participación, contribuyendo a la atracción y apego del evento al fomentar y potenciar el sentido de comunidad.

Criterio 5: suficiencia de capital. La base de capital es un regalo de dinero o propiedad que produce ingresos a una organización pública (como un hospital o una universidad) para un propósito específico, por ejemplo, la investigación o las becas. En general, el activo dotado se mantiene intacto y sólo los ingresos generados se consumen (Jeong B., 2013). Se espera que las organizaciones experimenten menos financiación y por tanto menos interrupción del programa si depende más de un fondo patrimonial, de su renta de la inversión asociada y de inversores con alta recurrencia (Keating, et al. 2005). Una práctica que ayuda a conseguir suficiencia en el capital es el fortalecimiento de las relaciones con los inversionistas.

Cuando se trata de fortalecer la relación con los inversionistas, es importante reconocer que la manera como se comunica el valor es tan importante como lo que se comunica (Rasler, 2007), proporcionando una clara conexión entre el apoyo financiero dado y el impacto del programa, traducido en la prestación de servicios u otros aspectos organizativos Rasler, 2007; Jeong B. 2013; Sontag, Staplefoote, \& Gonzalez, 2012).

Establecer líneas abiertas de comunicación con los inversores ayuda a alinear sus prioridades con la misión social de la organización y a fomentar una relación construida en la veracidad y la transparencia. Como resultado, los inversores están más motivados a apoyar financieramente las Beyoungri Danche en el largo plazo (Sontag et al., 2012). 


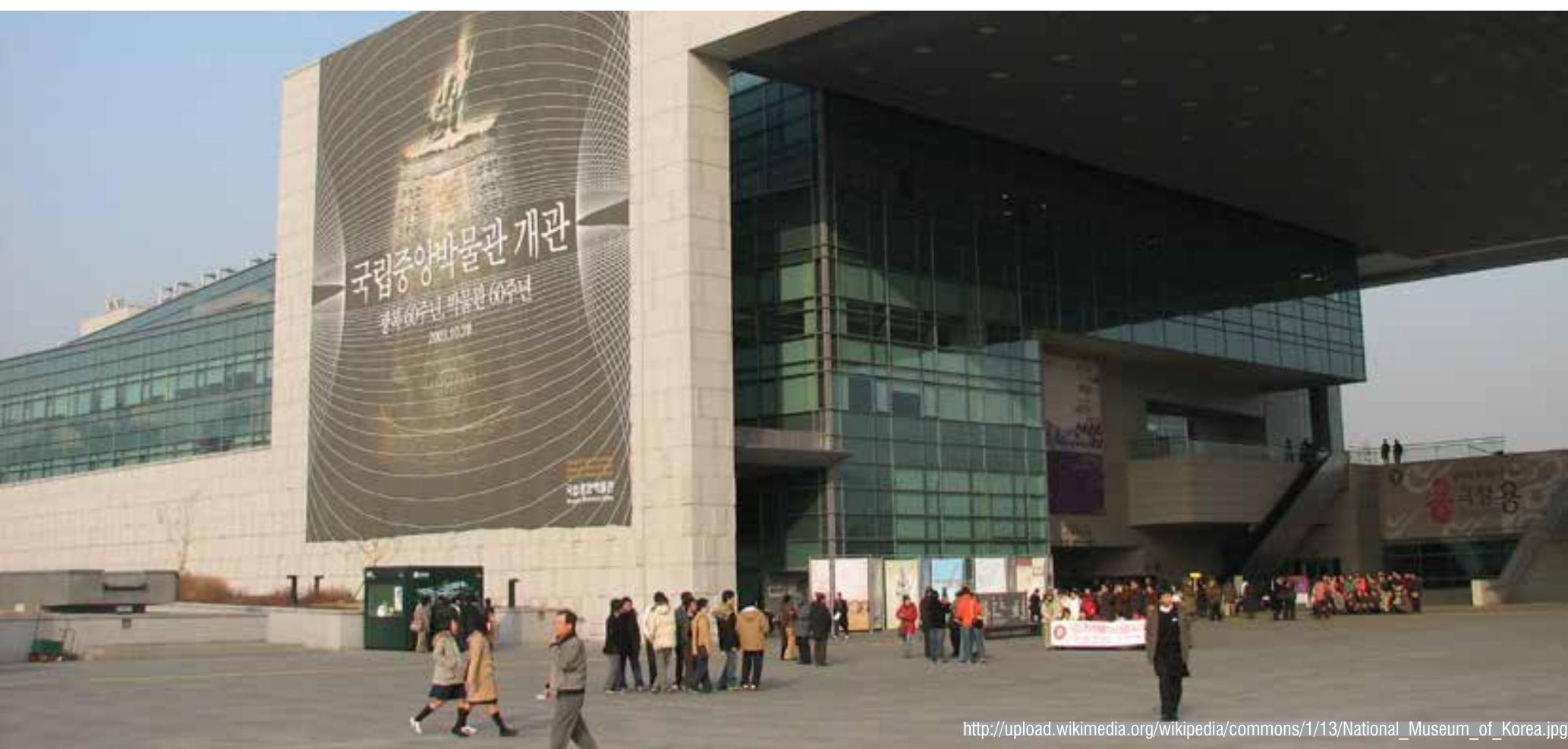

\section{Investigación exploratoria web y contextualización de las be- youngri danche exitosas de corea del sur}

Para propósitos de este trabajo se elabora una investigación exploratoria de contenidos web que identifica prácticas de sostenibilidad financiera en tres Beyoungri Danche exitosas, establecidas en Corea del Sur: Korea animals rights advocates, National museum of Korea y Greenpeace Korea. Utilizando la evaluación para sitios web diseñada por la alianza entre la fundación Learning By Giving y la Northeastern University de Boston, cuya misión es avanzar en la comprensión de la nueva generación de filantropía, proporcionando las herramientas financieras, tecnológicas e intelectuales para examinar el impacto de las Beyoungri Danche en la comunidad.

La investigación exploratoria de contenido es una técnica de análisis destinada a formular, a partir de ciertos datos, inferencias reproducibles y válidas que puedan aplicarse a su contexto, y comprende operaciones que permiten el procesamiento de datos de forma científica (Krippendor, 1990). En la actualidad es utilizada como una técnica investigativa, sistemática, objetiva y cuantitativa del contenido de las comunicaciones (Bardin, 2002). A continuación se contextualizan las Beyoungri Danche seleccionadas para este análisis, con información tomada de sus sitios web oficiales:

Korea Animals Rights Advocates (KARA). Es una organización sin ánimo de lucro exitosa, reconocida por los medios y apoyada por los animalistas. Plantean que los animales tienen derecho a vivir sus vidas libres de la tiranía y el sufrimiento. La explotación y el abuso de los animales es un problema importante en Corea, agravado por la débil aplicación de la protección de los animales y un público desinformado. KARA trabaja para educar al público acerca de las cuestiones éticas en torno a la protección de animales en Corea.

National Museum of Korea. El Museo Nacional de Corea es el museo emblemático de la historia y el arte en Corea del Sur. Desde su creación en 1945, ha estado comprometido con diversos estudios y actividades de investigación en los campos de la arqueología, historia y arte, en continuo desarrollo de una variedad de exposiciones y programas de educación. Desde su traslado al distrito de Yongsan en 2005, el museo ha atraído a 20 millones de visitantes. 
Greenpeace Korea. Greenpeace es una organización no lucrativa que está en varios países del mundo, Greenpeace Corea ha sido una de las sedes que ha logrado un poder de voluntariado exponencial. Es una organización independiente, que utiliza la confrontación creativa para exponer los problemas ambientales globales y dar soluciones que son esenciales para un futuro verde y pacífico. El objetivo de Greenpeace es asegurar la capacidad de la tierra para nutrir la vida en toda su diversidad.

La tabla 1 muestra las prácticas en cada una de las organizaciones sujetas al estudio, identificadas por medio de la investigación exploratoria de contenidos web.

Tabla 1. Las buenas prácticas financieras identificadas en la investigación exploratoria de las beyoungri danche exitosas en corea del sur.

Fuente: Kara: http://animalrightskorea.org/. NMK: http://www.museum.go.kr/site/main/index002. GK: http://www.greenpeace.org/korea/.

\begin{tabular}{|c|c|c|c|c|}
\hline CRITERIOS & PRÁCTICAS A EVALUAR & $\begin{array}{l}\text { KOREA ANIMALS RIGHTS } \\
\text { ADVOCATES }\end{array}$ & NATIONAL MUSEUM OF KOREA & GREENPEACE KOREA \\
\hline \multirow{3}{*}{ 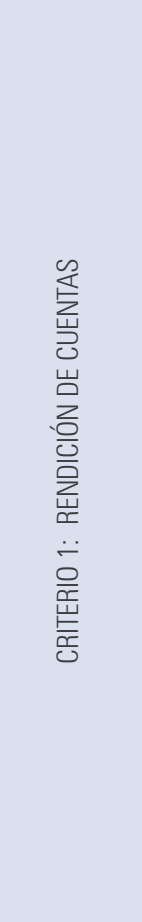 } & $\begin{array}{l}\text { 1. La organización muestra evidencia } \\
\text { de contabilidad y de que sus finanzas } \\
\text { son bien gestionadas. }\end{array}$ & $\begin{array}{l}\text { Presenta una lista de actividades que } \\
\text { han representado gastos con eviden- } \\
\text { cias fotográficas, citando el monto } \\
\text { de la donación recibida para cada } \\
\text { una. Muestra informes de gestión, a } \\
\text { través de las noticias generales publi- } \\
\text { cadas periódicamente. }\end{array}$ & $\begin{array}{l}\text { Muestra detalladamente estados fi- } \\
\text { nancieros como el balance general y } \\
\text { el estado de resultados, auditados y } \\
\text { de acuerdo con los principios genera- } \\
\text { les de contabilidad. }\end{array}$ & $\begin{array}{l}\text { Reporta resultados anuales a INGO } \\
\text { Accountability charter, que es una } \\
\text { iniciativa global de apoyo a las orga- } \\
\text { nizaciones no lucrativas, dando lugar } \\
\text { a mejoras en la presentación de re- } \\
\text { portes estandarizados que garantizan } \\
\text { la credibilidad del proceso de infor- } \\
\text { mación y proporciona confianza a los } \\
\text { grupos de interés. }\end{array}$ \\
\hline & $\begin{array}{l}\text { 2. Se compromete con la evaluación } \\
\text { de su desempeño y las medidas utili- } \\
\text { zadas para evaluar son adecuadas, de- } \\
\text { mostrando que el beneficio propuesto } \\
\text { en la misión de la organización está } \\
\text { siendo proveído a los beneficiarios. }\end{array}$ & $\begin{array}{l}\text { Mide sus resultados con el número } \\
\text { de animales rescatados por año y la } \\
\text { atención veterinaria que reciben. El alto } \\
\text { impacto de éstos en Corea, deja ver el } \\
\text { cumplimiento a cabalidad de su misión. }\end{array}$ & $\begin{array}{l}\text { Muestra listas de chequeo de inspec- } \\
\text { ción pública abierta que evalúan punto } \\
\text { por punto la gestión de la organización. } \\
\text { El reporte anual de gestión es com- } \\
\text { pleto e incluye comparativos con ba- } \\
\text { lances de años anteriores para medir } \\
\text { su desempeño. Existe una política de } \\
\text { gestión de colecciones, que garantiza } \\
\text { entre otras cosas que el público disfru- } \\
\text { te del arte del museo. }\end{array}$ & $\begin{array}{l}\text { Evalúa su desempeño de manera rigu- } \\
\text { rosa, a través de INGO que audita sus } \\
\text { reportes en cuanto a: respeto por los } \\
\text { derechos humanos, independencia, } \\
\text { transparencia, buen gobierno, promo- } \\
\text { ción responsable, participación, diver- } \\
\text { sidad e inclusión, medioambiente, re- } \\
\text { caudación ética y gestión profesional; } \\
\text { indicando las mejoras para atender a } \\
\text { sus beneficiarios. }\end{array}$ \\
\hline & $\begin{array}{l}\text { 3. Hay una relación lógica entre las } \\
\text { actividades de la organización y los } \\
\text { resultados que busca. }\end{array}$ & $\begin{array}{l}\text { Logra que las actividades de adopción } \\
\text { y promoción del cuidado animal sur- } \\
\text { tan efecto en el número de mascotas } \\
\text { rescatadas. Los programas van desde } \\
\text { la sensibilización, hasta la acción de } \\
\text { toda la comunidad surcoreana. }\end{array}$ & $\begin{array}{l}\text { Muestra la gran acogida por parte de } \\
\text { la comunidad local y mundial a las } \\
\text { actividades que se proponen dentro } \\
\text { de los programas del museo, respon- } \\
\text { diendo de manera atenta, participati- } \\
\text { va y aglomerada. }\end{array}$ & $\begin{array}{l}\text { Logra que sus actividades para cam- } \\
\text { biar actitudes y comportamientos en } \\
\text { pro del medio ambiente, se traduzcan } \\
\text { en victorias de alto impacto y las } \\
\text { muestra al mundo. }\end{array}$ \\
\hline
\end{tabular}




\begin{tabular}{|c|c|c|c|c|}
\hline \multirow{4}{*}{ 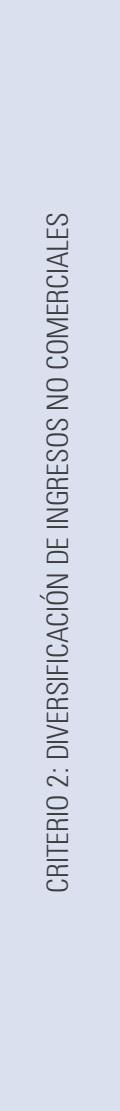 } & $\begin{array}{l}\text { 1. El modelo de negocios es clara- } \\
\text { mente definido, provee suficiente } \\
\text { información para transmitir los tipos } \\
\text { de fondos que recibe. }\end{array}$ & $\begin{array}{l}\text { Informa acerca de las fuentes de } \\
\text { financiación como donantes, celebri- } \\
\text { dades y compañías. }\end{array}$ & $\begin{array}{l}\text { Reporta una lista de donantes: } \\
\text { personas jurídicas o naturales con } \\
\text { suficiente información en cifras, } \\
\text { nombres, servicios proveídos y be- } \\
\text { neficios obtenidos. }\end{array}$ & $\begin{array}{l}\text { No acepta donaciones de gobiernos } \\
0 \text { corporaciones para mantener su } \\
\text { independencia. Se basa en las contri- } \\
\text { buciones de partidarios individuales y } \\
\text { subvenciones de fundaciones. }\end{array}$ \\
\hline & $\begin{array}{l}\text { 2. Demuestra una conexión lógica en- } \\
\text { tre el trabajo que hace y como asegu- } \\
\text { ra el dinero para apoyar ese trabajo. }\end{array}$ & $\begin{array}{l}\text { Establece redes con empresas que } \\
\text { pueden ser afines a alguna de sus ac- } \\
\text { tividades, logrando conectar miles de } \\
\text { socios e invesionistas en toda Corea, } \\
\text { quienes hacen sus donaciones online. }\end{array}$ & $\begin{array}{l}\text { Presenta una forma organizada y } \\
\text { efectiva para realizar sus labores, } \\
\text { respaldada por la financiación de múl- } \\
\text { tiples fuentes. Esto se debe a la di- } \\
\text { versidad de sus programas, a los que } \\
\text { acuden diferentes tipos de público. }\end{array}$ & $\begin{array}{l}\text { Se llevan campañas locales desde } \\
\text { la oficina de Corea del Sur y se pro- } \\
\text { porciona apoyo estratégico a las ofi- } \\
\text { cinas internacionales, financiándose } \\
\text { por millones de miembros en todo el } \\
\text { mundo. }\end{array}$ \\
\hline & $\begin{array}{l}\text { 3. La organización ha diversificado } \\
\text { sus fuentes de financiación y parecen } \\
\text { viables en el futuro y resistentes con- } \\
\text { tra variaciones económicas. }\end{array}$ & $\begin{array}{l}\text { Cuenta con donaciones recurrentes } \\
\text { de diversas fuentes tanto de perso- } \\
\text { nas jurídicas como naturales, Imple- } \\
\text { mentan círculos de donación y susb- } \\
\text { cripciones con activación periódica. }\end{array}$ & $\begin{array}{l}\text { Las fuentes de financiación son múl- } \\
\text { tiples debido a que se ajustan según } \\
\text { el tipo de programa ofrecido. Ade- } \\
\text { más de donaciones de figuras jurí- } \\
\text { dicas y personas naturales, también } \\
\text { reciben donaciones por membresías, } \\
\text { asistencia eventos, programas fami- } \\
\text { liares y para niños. }\end{array}$ & $\begin{array}{l}\text { Tienen un sistema de contribución } \\
\text { incremental que asegura fondos } \\
\text { suficientes, con altos ingresos; los } \\
\text { redirige a oficinas de regiones en de- } \\
\text { sarrollo. Implementan la recaudación } \\
\text { masiva de fondos y los mensajes de } \\
\text { activación. }\end{array}$ \\
\hline & $\begin{array}{l}\text { 4. Demuestra a los donantes que su } \\
\text { apoyo es valioso y es capaz de cum- } \\
\text { plir con sus expectativas. }\end{array}$ & $\begin{array}{l}\text { Reconoce que los donantes y socios } \\
\text { son cruciales para ayudar a la orga- } \\
\text { nización en su esfuerzo para salvar } \\
\text { todas las mascotas. Responde a las } \\
\text { expectativas de los donantes cum- } \\
\text { pliendo la misión social, demostrán- } \\
\text { dolo en cifras y haciéndolo visible en } \\
\text { los medios. }\end{array}$ & $\begin{array}{l}\text { Cumple tanto con los objetivos mi- } \\
\text { sionales, como con las expectativas } \\
\text { de los donantes, ofreciéndoles retri- } \\
\text { buciones traducidas en beneficios de } \\
\text { la entrada al museo, y asistencia a } \\
\text { eventos exclusivos. }\end{array}$ & $\begin{array}{l}\text { Agradecen a través de un correo perso- } \\
\text { nalizado cada donación o firma que la } \\
\text { comunidad coreana hace para alcanzar } \\
\text { las objetivos por los que luchan. "Gra- } \\
\text { cias por firmar, gracias por manifestar- } \\
\text { se, gracias por donar, gracias por tomar } \\
\text { acción, gracias por levantar la petición," } \\
\text { son algunos de los reconocimientos } \\
\text { que hacen a nivel individual. Sus victo- } \\
\text { rias por el medio ambiente cumplen las } \\
\text { expectativas de su comunidad. }\end{array}$ \\
\hline 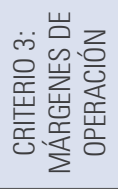 & $\begin{array}{l}\text { 1. Los ingresos son iguales o mayores } \\
\text { que sus gastos; la organización no } \\
\text { está en déficit. }\end{array}$ & No muestra evidencia. & No muestra evidencia. & $\begin{array}{l}\text { Reportan déficit al año } 2013 \text { de } € 6,8 \\
\text { millones, justificados en un aumento } \\
\text { de sus activos necesarios para el so- } \\
\text { porte de actividades que luchan por } \\
\text { el medio ambiente. }\end{array}$ \\
\hline 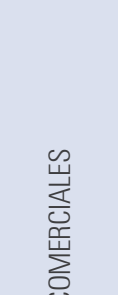 & $\begin{array}{l}\text { 1. La organización ha emprendido ac- } \\
\text { tividades comerciales. }\end{array}$ & No muestra evidencia. & $\begin{array}{l}\text { Tiene ingresos comerciales de múl- } \\
\text { tiples fuentes. Las cafeterías, bares, } \\
\text { terrazas y cafés dentro del museo son } \\
\text { unas de ellas, así como, los recorridos } \\
\text { por el jardín, el internado de verano y } \\
\text { por supuesto la tienda, donde se ven- } \\
\text { den joyas, relojes, bolsos, libros y obras } \\
\text { decorativas de la cultura coreana. }\end{array}$ & $\begin{array}{l}\text { No ha emprendido actividades co- } \\
\text { merciales. }\end{array}$ \\
\hline 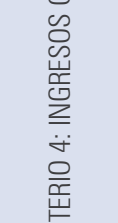 & $\begin{array}{l}\text { 2. Las actividades comerciales de la } \\
\text { organización son independientes de } \\
\text { las misionales }\end{array}$ & No muestra evidencia. & $\begin{array}{l}\text { Las actividades comerciales del mu- } \\
\text { seo no son independientes de las } \\
\text { misionales, debido a que su campo } \\
\text { de acción repercute en los objetivos } \\
\text { misionales de la organización, ade- } \\
\text { más operan dentro del mismo museo. }\end{array}$ & No aplica. \\
\hline ్ㅗㅇ & $\begin{array}{l}\text { 3. La organización realiza eventos de } \\
\text { los que obtiene ingresos por suscrip- } \\
\text { ciones y ventas. }\end{array}$ & No muestra evidencia. & $\begin{array}{l}\text { Eventos como conferencias, conver- } \\
\text { satorios de galería, fiestas de noche } \\
\text { y celebraciones de gala, se presen- } \\
\text { tan regularmente, dejando ingresos } \\
\text { significativos. }\end{array}$ & $\begin{array}{l}\text { Eventos de carácter deportivo con pa- } \\
\text { trocinadores, pago de inscripción con } \\
\text { el objetivo de recaudación. Se desta- } \\
\text { ca que se pone una meta en el monto } \\
\text { de ingresos a alcanzar en cada uno. }\end{array}$ \\
\hline 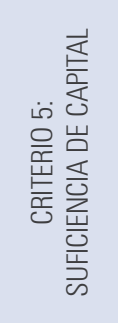 & $\begin{array}{l}\text { 1. Ofrece una fuerte propuesta de va- } \\
\text { lor para los inversionistas, articulando } \\
\text { y haciendo atractivo su mensaje para } \\
\text { el tipo de inversionista que busca }\end{array}$ & $\begin{array}{l}\text { Ofrece múltiples oportunidades para } \\
\text { hacer crecer la marca de las empre- } \\
\text { sas inversionistas, presencia dentro } \\
\text { del sector, exposición a la base de } \\
\text { apasionados, donantes, voluntarios y } \\
\text { asistentes a eventos, además tráfico } \\
\text { web. El mensaje es altamente atrac- } \\
\text { tivo y explícito. }\end{array}$ & $\begin{array}{l}\text { Muestra círculos en los que los inver- } \\
\text { sionistas y donantes pueden participar. } \\
\text { Según sea el monto de su inversión, } \\
\text { esos círculos describen un sinnúme- } \\
\text { ro de actividades y beneficios como: } \\
\text { eventos especiales de noche cuando el } \\
\text { museo está cerrado al público, entrada } \\
\text { libre y gratuita durante un año para to- } \\
\text { dos los empleados y un invitado. }\end{array}$ & $\begin{array}{l}\text { Estimula prácticas corporativas sen- } \\
\text { sibles al medio ambiente como me- } \\
\text { canismo regulatorio para interesar a } \\
\text { los negocios en las preocupaciones } \\
\text { ambientales y comprometerlos de } \\
\text { manera estratégica, como aliados } \\
\text { confiables a través de green alliances. }\end{array}$ \\
\hline
\end{tabular}




\section{RESULTADOS Y CONCLUSIONES}

Una Beyoungri Danche es financieramente sostenible, cuando a corto, mediano y largo plazo puede mantener equilibrio en el balance haciendo rendición de cuentas, diversificar y distribuir las fuentes de ingresos, obtener márgenes de operación altos, generar ingresos comerciales y mantener una base de capital suficiente.

Mantener una contabilidad confiable, utilizar un programa de evaluación para demostrar valor, utilizar los informes anuales para comunicar resultados, desarrollar un plan de recaudación de fondos coherente, incorporar técnicas innovadoras de recaudación de fondos, aumentar ingresos y reducir gastos operativos, emprender actividades comerciales en forma gradual, separar la actividad comercial, realizar grandes eventos y fortalecer las relaciones con los inversionistas, son algunas de las buenas prácticas encontradas en la literatura, para que una Beyoungri Danche sea sostenible financieramente en el tiempo.

El acelerado crecimiento económico coreano permitió el surgimiento de organizaciones filantrópicas que benefician a la comunidad coreana y mundial, en las que se pueden identificar buenas prácticas de gestión y particularmente buenas prácticas financieras, demostrando que los resultados financieros de las Beyoungri Danche son un medio para el cumplimiento de su misión social.

La evaluación utilizada en la investigación exploratoria de contenidos web, es una herramienta que permite a las Beyoungri Danche, visualizar su salud financiera identificando las buenas prácticas que cumplen, y poniendo en acción las que no cumplen, para lograr la sostenibilidad en el largo plazo.

Es clave para las partes de interés de una Beyoungri Danche que el informe anual deba contener, con evidencias, las actividades realizadas, los gastos incurridos, las fuentes de ingresos, las donaciones recibidas y una sección de contabilidad estandarizada a nivel internacional que garantice y permita a los interesados interactuar y a los usuarios cada vez más globales conocer y realizar sus donaciones.

\section{Referencias Bibliográficas}

- Abraham, A. (2003). Financial sustainability and accountability: a model for nonprofit organizations. AFAANZ CONFERENCE PROCEEDINGS , 26-46.

- $\quad$ Alexander, J., Nank, R., \& Stivers, C. (1999). Implications of welfare reform: Do nonprofit survival strategies threaten civil society. Nonprofit and Voluntary Sector Quarterly, 452-475.

- $\quad$ Anheier, H. K., \& Seibel, W. (2001). The nonprofit sector in Germany. Between state, economy and society. Manchester: Manchester University Press.

- $\quad$ ANTHONY, R., \& YOUNG, D. (1994). Accounting and financial management. The Jossey-Bass handbook of nonprofit leadership and management, 403-443.

- Austin, J., Stevenson, H. \& Wei-Skillern, J. (2006). Social and commercial entrepreneurship: same, different, or both? Entrepreneurship Theory and Practice, 1-22.

- $\quad$ Bak, S.-P. (2001). NGO and Modern Society. Seoul.

- Bardin, L. (2002). El análisis de contenido. España Ediciones Akal S.A.: Traducción de Cesar Suarez. 3er edición.

- Bell, J., Masoka, J., \& Zimmerman, S. (2010). Nonprofit sustainability: making strategic decisions for financial viability. San Francisco.

- Bessel, K., Williams, C. L., \& Klak, J. (2011). Nonprofit sustainability during times of uncertainty. Nonprofit management and leadership , 53-65.

- $\quad$ Bidet, E. (2002). Explaining the Third Sector in South Korea. Journal of Voluntary and Nonprofit Organizations, 131-147.

- $\quad$ Boeuf, B., Darveau, J., \& Legoux, R. (2014). Financing creativity: Crowdfunding as a new approach for theatre projects. International Journal of Arts Management, 33-48.

- $\quad$ Boschee, J. (1995). Social entrepreneurship. Across the Board, 20-25.

- Boschee, J., \& Mcclurg, D. (2003). Toward a Better Understanding of Social Entrepreneurship: Some Important Distinctions. Institute for Social Entrepreneurs, Minnesota.

- Bowman, W. (2011). Financial Capacity and Sustainability of Ordinary Nonprofits. Nonprofit management and leadership, 37-51.

- Bray, I. (2010). Effective fundraising for nonprofits: Real-world strategies that work. Berkley, Calif.: 3rd ed. 
- Brinckerhoff, P. (2000). Social Entrepreneurship: The Art of Mission-Based Venture Development. New York: John Wiley.

- Bryce, H. (1992). Financial and Strategic Management for Nonprofit Organizations. Englewood Cliffs, New Jersey:: Prentice Hall.

- Buchheit, s., \& Parsons, L. M. (2006). An experimental investigation of accounting information's influence on the individual giving process. Journal of accounting and public policy, 666-686.

- Carman, J. G. (2001). Community foundations: A growing resource for community development . nomprofit management and leadership, 7-24.

- Carroll, D., \& Stater, K. (2009). Revenue diversification in nonprofit organizations: does it lead to financial stability? Journal of Public Administration Research and Theory, 974-966.

- Cho, D. (2007). Social Movement \& non-govermental organizations in SOUFT KOREA. Seoul: Arche.

- Choi, S., \& Yang, S. (2011). Understanding Challenges and Opportunities in the Nonprofit Sector in Korea. International Review of Public Administration, 51-69.

- Chung, C.-H. (2003). The Locus of Civil Society in Korea: Dynamics since 1970s. Seoul.

- Driessens, O., Joye, S., \& Biltereys, D. (2012). The X-factor of charity: a critical analysis of celebrities' involvement in the 2010 Flemish and Dutch Haiti relief shows. Media culture \& society, 709-725.

- Echeverri, 0. (2008). Mercantilización de los servicios de salud para el desarrollo: el caso de Colombia. Rev Panam Salud Publica, 210-216.

- Eikenberry, A. M. (2008). Fundraising in the new philanthropy environment: The benefits and challenges of working with giving circles. Nonprofit management and leadership , 141-152.

- ELKIN, R. (1985). Paying the Piper and Calling the Tune: Accountability in the Human Service. Administration in Social Work, 13- 26.

- Filo, K. R., Funk, D. C., \& O'Brien, D. (2008). It's really not about the bike: Exploring attraction and attachment to the events of the Lance Armstrong Foundation. JOURNAL OF SPORT MANAGEMENT, 501-525.

- Frumkin, P., \& Andre-Vlark, A. (2000). When missions, markets, and politics collide: Values and strategy in the nonprofit human services. Nonprofit and Voluntary Sector Quarterly, 141-163.

- Giroud. (2011). Corporate governance, product market competition, and equity prices. Journal of Finance, 563-600.

- Giroud, X., \& Mueller, H. (2010). Does corporate governance matter in competitive industries? Journal of Financial Economics, 312-331.

- Gordon, T. P., Khumawala, S. B., Kraut, m., \& Neely, D. G. (2010). Five dimensions of effectiveness for nonprofit annual reports. Nonprofit management and leadership, 209-228.

- HACKLER, D., \& SAXTON, G. D. (2007). The strategic use of information technology by nonprofit organizations: Increasing capacity and untapped potential. Public administration review, 474-487.

- Holtzhausen, L. (2013). Non-profit organizations bridging the communication divide in a complex South Africa. Public Relations Review, 2-8.

- Jeong, B. (2013). Accountability in south korean nonprofit organizations: stakeholder expectations as perceived by nonprofit leaders. University of Pittsburgh: Graduate School of Public and International Affairs.

- Jeong, S. (2008). The study on the solutions for financial crisis of NGOs in Korea. Dong-seo Yeonkoo (Eastern and Western Studies), 249-276.

- Jung, K., \& Moon, M. (2007). The Double-Edged Sword of Public-Resource Dependence: The Impact of Public Resources on Autonomy and Legitimacy in Korean Cultural Nonprofit Organizations. Policy Studies Journal, 205-226.

- Keating, e., Fischer, M., Gordon, T., \& Greenlee, J. (2005). Assessing Financial Vulnerability in the nonprofit sector. John F. Kennedy School of government, Harvard University, 224-265.

- Kellock Hay, G., Beattie, R. S., Livingstone, R., \& Munro, P. (2001). Change, HRM and the voluntary sector. Employee Relations, 23, 240-255.

- Kerlin, J. (2005). Social enterprise in the United States and Europe: understanding and learning from the differences. Voluntas, 247-263.

- Kim, H. (1997). South Korean NGOs: Global Trend and Prospect. Global Economic Review, vol. 26, no. 2, pp. 93-115.

- Kim, I., \& Hwang, C. (2002). Defining the Nonprofit Sector: South Korea. THE JOHNS HOPKINS COMPARATIVE NONPROFIT SECTOR PROJECT, 2-28.

- Kim, J. (2006). Government and NGO. Seou South Korea: Pakyoungsa.

- Krippendor, K. (1990). Metodologia de análisis de contenido teoría y práctica. España Ediciones Paidós Ibérica S.A. ISBN: 84-7509-627-1. 1er edición. Traducción de Leandro wolfson. P 28.

- Lyons, M., \& Samiul, H. (2002). Researching Asia's Third Sector. International Journal of Voluntary and Nonprofit Organizations, 107-112.

- Machlup, F. (1967). Theories of the firm: Marginalist, behavioral, managerial. American Economic Review, $1-33$.

- MAGLIERI, G. (1997). Non-profit Organizations. FACES N5, 95-127.

- Mosley, J. E., Maronick, M. P., \& Katz, H. (2012). How organizational characteristics affect the adaptive tactics used by human service nonprofitmanagers confronting financial uncertainty. NONPROFIT MANAGEMENT \& LEADERSHII, 281-303.

- Park, S., \& Kim, Y. (2004). The Present Situations and Solutions of NGO in Korea. Sangmyung University 20. 
- Parsons, I. M. (2007). The impact of financial information and voluntary disclosures on contributions to Not-for-Profit organizations. Behavioral research in accounting, 179-196.

- Rasler, T. (2007). ROI for nonprofits: the new key to sustainability. Hoboken, N.J. : Wiley.

- Salamon, I. M. (2002). The resilient sector: The state of nonprofit America. En Salamon, L. M, The state of nonprofit America (págs. 3-61). Washington: Brookings Institution Press.

- $\quad$ Sang \& Seung, (2012). UNDERSTANDING CHALLENGES AND OPPORTUNITIES IN THE NONPROFIT SECTOR IN KOREA. International Review of Public Administration, 51-71.

- Sidel, M. (2010). The Promise and Limits of Collective Action for Nonprofit Self-Regulation: Evidence From Asia. Nonprofit and Voluntary Sector Quarterly, 1040-1056.

- Sirianni, C., \& Friedland, I. (2001). Civic Innovation in America: Community Empowerment, Public Policy and the Movement for Civic Renewal. Berkeley, CA: University of California press.

- Sontag, I. M., Staplefoote, I., \& Gonzalez, K. (2012). Financial Sustainability for Nonprofit Organizations. RAND HEALTH and RAND EDUCATION, 1-32.

- SOPHER, M. (1998). Setting Up a Control System. Nonprofit World, 45-47, Vol. 16.

- Thompson, J. (2002). The world of the social entrepreneur. The International Journal of Public Sector Management, 412-431.

- Trussel, J. (2002). "Revising the prediction of financial vulnerability". Nonprofit Management and Leadership, 17-31.

- Tuckman, H., \& Chang, C. (1991). A Methodology for Measuring the Financial Vulnerability of Charitable Nonprofit Organizations. Nonprofit and voluntary sector quarterly, 445-460.

- Wallace, S. (1999). Social entrepreneurship: the role of social purpose enterprises in facilitating community economic development. Journal of Developmental Entrepreneurship, 153-174.

- YOUNG, D. \&. (2008). Social Entrepreneurship and the Financing of Third Sector Organizations. Journal of Public Affairs Education, 547-567.

- ZIMMERMAN, J., \& STEVENS, B. W. (2006). The use of performance measurement in South Carolina Nonprofits. Nonprofit management and leadership, 315-327. 